\title{
Create Better Diversified High-Conviction Equity Portfolios using the Portfolio Diversification Index
}

\author{
Dominiek P. Crezée, and Laurens A.P. Swinkels
}

\begin{tabular}{|l|l|}
\hline \multicolumn{2}{|l|}{ ERIM REPORT SERIES RESEARCH IN MANAGEMENT } \\
\hline ERIM Report Series reference number & ERS-2010-038-LIS \\
\hline Publication & March 2010 \\
\hline Number of pages & 21 \\
\hline Persistent paper URL & \\
\hline Email address corresponding author & Iswinkels@ese.eur.nl \\
\hline Address & Erasmus Research Institute of Management (ERIM) \\
& RSM Erasmus University / Erasmus School of Economics \\
& Erasmus Universiteit Rotterdam \\
& P.O.Box 1738 \\
& 3000 DR Rotterdam, The Netherlands \\
& Phone: + 31 10 408 1182 \\
& Fax: $\quad+3110408$ 9640 \\
& Email: info@erim.eur.nl \\
& Internet: $\quad$ www.erim.eur.nl \\
\hline
\end{tabular}

Bibliographic data and classifications of all the ERIM reports are also available on the ERIM website: www.erim.eur.nl 


\section{ERASMUS RESEARCH INSTITUTE OF MANAGEMENT}

\section{REPORT SERIES}

\section{RESEARCH IN MANAGEMENT}

\begin{tabular}{|l|l|}
\hline ABSTRACT AND KEYWORDS \\
\hline Abstract & $\begin{array}{l}\text { We investigate the construction of well-diversified high-conviction equity portfolios, building on } \\
\text { Rudin and Morgan (2006) who introduced the Portfolio Diversification Index (PDI) as a new } \\
\text { measure of portfolio diversification applied to long/short equity hedge funds in an in-sample } \\
\text { period. We are the first to investigate the out-of-sample properties of the PDI. Our research } \\
\text { applies a novel portfolio selection algorithm to maximize the PDI of a portfolio of stocks in the } \\
\text { S\&P 500 Index over 2000 to 2009. We construct equally-weighted, well-diversified portfolios, } \\
\text { consisting of } 5 \text { to 30 stocks and compare these with randomly selected portfolios of the same } \\
\text { stock sizes. Our results indicate that investors using our algorithm to maximize the PDI can } \\
\text { improve the diversification of high-conviction equity portfolios. For example, a portfolio of } 20 \\
\text { stocks constructed using the algorithm with the PDI behaves out-of-sample as if it contains 10 } \\
\text { independent stocks, i.e. a PDI score of 10. Although this is less than the PDI score of 15 } \\
\text { achieved in-sample, it is a significant improvement over the PDI score of 7, which occurs with a } \\
\text { randomly selected portfolio. Our research is robust with respect to the number of stocks in the } \\
\text { investment portfolio and the time period under consideration. }\end{array}$ \\
\hline Free Keywords & diversification, portfolio construction, risk reduction \\
\hline Availability & $\begin{array}{l}\text { The ERIM Report Series is distributed through the following platforms: } \\
\text { Academic Repository at Erasmus University (DEAR), DEAR ERIM Series Portal } \\
\text { Social Science Research Network (SSRN), SSRN ERIM Series Webpage } \\
\text { Research Papers in Economics (REPEC), REPEC ERIM Series Webpage }\end{array}$ \\
\hline Classifications & $\begin{array}{l}\text { The electronic versions of the papers in the ERIM report Series contain bibliographic metadata } \\
\text { by the following classification systems: } \\
\text { Library of Congress Classification, (LCC) LCC Webpage } \\
\text { Journal of Economic Literature, (JEL), JEL Webpage } \\
\text { ACM Computing Classification System CCS Webpage } \\
\text { Inspec Classification scheme (ICS), ICS Webpage }\end{array}$ \\
\hline
\end{tabular}




\title{
Create better diversified high-conviction equity portfolios
}

\section{using the Portfolio Diversification Index*}

\author{
Dominiek P. Crezée \\ Erasmus School of Economics \\ Laurens A. P. Swinkels \\ Erasmus School of Economics \\ Erasmus Research Institute of Management \\ Robeco Quantitative Strategies \\ 1swinkels@ese.eur.nl
}

Web: http://people.few.eur.nl/lswinkels

March 2010

\footnotetext{
* We would like to thank excellent research assistance from the Erasmus Data Team and Liz Bond for valuable editorial assistance. The views in this paper are not necessarily shared by Robeco or any of its subsidiaries.
} 


\title{
Create better diversified high-conviction equity portfolios using the Portfolio Diversification Index
}

\begin{abstract}
We investigate the construction of well-diversified high-conviction equity portfolios, building on Rudin and Morgan (2006) who introduced the Portfolio Diversification Index (PDI) as a new measure of portfolio diversification applied to long/short equity hedge funds in an in-sample period. We are the first to investigate the out-of-sample properties of the PDI. Our research applies a novel portfolio selection algorithm to maximize the PDI of a portfolio of stocks in the S\&P 500 Index over 2000 to 2009. We construct equally-weighted, well-diversified portfolios, consisting of 5 to 30 stocks and compare these with randomly selected portfolios of the same stock sizes. Our results indicate that investors using our algorithm to maximize the PDI can improve the diversification of high-conviction equity portfolios. For example, a portfolio of 20 stocks constructed using the algorithm with the PDI behaves out-of-sample as if it contains 10 independent stocks, i.e. a PDI score of 10. Although this is less than the PDI score of 15 achieved in-sample, it is a significant improvement over the PDI score of 7, which occurs with a randomly selected portfolio. Our research is robust with respect to the number of stocks in the investment portfolio and the time period under consideration.
\end{abstract}

Keywords: Diversification, Portfolio construction, Risk reduction

\# words 4229 


\section{INTRODUCTION}

Obtaining a well-diversified stock portfolio has become easier for private investors through financial innovations such as index mutual funds or exchange traded funds. ${ }^{1}$ Nevertheless, private investors and portfolio managers who follow high-conviction strategies with a high active-share as defined by Cremers and Petajisto (2009) may want to know whether their portfolio is well diversified. Malkiel (1990) claims that: "By the time the portfolio contains close to 20 equalized and well-diversified issues, the total risk (standard deviation of returns) of the portfolio is reduced by 70 percent. Further increase in the number of holdings does not produce any significant further risk reduction." In this paper, our focus is to investigate how an investor can construct a portfolio of "welldiversified issues."

In order to construct a well-diversified portfolio, we use a portfolio selection algorithm that maximizes the Portfolio Diversification Index (PDI), a measure of diversification that was introduced by Rudin and Morgan (2006). This quantitative method enables us to construct portfolios with good diversification properties. While Rudin and Morgan (2006) show that a portfolio based on the PDI is better diversified in-sample, they do not provide any evidence on the out-of-sample properties of their new methodology. They focus in their application on equity long/short hedge funds instead of equity portfolios considered in this research. In any real-life application it is important to know whether in-sample measures also hold out-of-sample. ${ }^{2}$ Our results suggest that the diversification properties of out-ofsample portfolios are also superior to randomly selected portfolios. This out-of-sample evidence is of key importance for investors wanting to apply the PDI in practice to form real-life investment portfolios. Our empirical results should convince investors about the added value of efficient diversification relative to naive diversification, which is the preferred diversification strategy according to De Wit (1998) and DeMiguel et al (2009).

\footnotetext{
${ }^{1}$ See, e.g., Agapova (2009) for more details on these investment vehicles.

${ }^{2}$ DeMiguel, Garlappi, and Uppal (2009) stress the importance of out-of-sample evidence when using models for diversification that require estimation and hence are prone to estimation risk.
} 
The well-diversified PDI portfolio consisting of 20 stocks acts as if it consists of 15 independent stocks in the in-sample period. Our out-of-sample results indicate that for a real-life investor who uses the PDI to construct a diversified portfolio, it behaves as if there are 10 independent stocks, which is a significant improvement on the randomly selected portfolio for which this number is 7 . An alternative measure for diversification indicates that the volatility of the portfolio declines from $30 \%$ of a single stock to $23 \%$ of a single stock when applying the PDI relative to a randomly selected portfolio. This means that the diversification gain is about $22 \%$. Our results hold both for annually and quarterly rebalanced portfolios, indicating that real-life investors may benefit from the PDI when constructing a diversified portfolio. These results are robust with respect to the number of stocks in the investment portfolio and the time period under consideration.

The remainder of this paper is organized as follows. In Section II we describe the data that we used in our analysis. In Section III we explain various diversification measures, with a focus on the Portfolio Diversification Index and the Diversification Ratio. Section IV contains the results from our empirical analysis. A conclusion is provided in Section V.

\section{DATA}

Our sample consists of the stocks comprising the Standard and Poor's (S\&P) 500 Index. We choose this sample of large and liquid stocks to prevent potential problems with price asynchronicity; see Epps (1979) or Dimson (1979). ${ }^{3}$ We obtain daily total-return stock prices from the Center for Research in Security Prices (CRSP). These total-return stock prices are adjusted for dividend payments and stock splits. The sample period covers ten years with daily stock prices collected on each trading day from January 2000 through December 2009. Daily returns are calculated based on the daily stock prices; excess daily returns are calculated by deducting the daily effective federal funds rate from the daily

\footnotetext{
${ }^{3}$ We advise investors who hold illiquid securities (such as small-cap stocks or emerging market stocks) in their portfolio to use a lower frequency of return observations. These could be overlapping in order to increase the number of observations and increase the precision of the estimated covariance matrix.
} 
return. The federal funds rate is a weighted average of rates on trades through New York brokers. It is available for each calendar day and was obtained from CRSP.

At the end of each calendar year, we check which stocks are in the S\&P 500 Index and include in our sample all stocks where a one-year historical return is available. Only a few stocks drop out of the sample in a given year because of this restriction. If any stocks are delisted during the investment period, we replace the missing values with the crosssectional average return of all the available stocks on each of the missing days. While this might influence the average return generated by the portfolios, we believe the diversification properties will be only marginally affected.

\section{MEASURING PORTFOLIO DIVERSIFICATION}

The PDI method put forward by Rudin and Morgan (2006) involves principal component analysis of the daily stock returns. They define the PDI as follows:

$$
P D I=2 \cdot \sum_{k=1}^{N} k \cdot W_{k}-1
$$

where $N$ represents the number of stocks in the portfolio, and $W_{k}$ is the ordered vector of principal component relative strengths based on the daily covariance matrix of stock returns.

For a completely non-diversified portfolio dominated by a single factor $\left(W_{1} \approx 1, W_{2 \leq k \leq N} \approx 0\right)$, the $P D I \approx 1$. For an ideally diversified portfolio, $W_{k} \approx 1 / N$ for each $k$, and $P D I \approx N$. Any positive change in front loading, when explanatory power moves from $W_{l}$ to $W_{k}$ with $l$ higher than $k$, reduces the index. In other words: the more the variation in portfolio returns is explained by common factors, the less favorable the diversification properties of the portfolio become.

An alternative measure for diversification was described by Markowitz (1976). We call this the Diversification Ratio. It is calculated as follows: 


$$
\text { Diversification Ratio }=\frac{1}{N}+\frac{N-1}{N} \times \frac{\overline{\operatorname{cov}}\left\{R_{i}, R_{j}\right\}}{\overline{\operatorname{var}}\left\{R_{j}\right\}}
$$

So, we define the Diversification Ratio as the ratio of the average covariance of the assets and the equally-weighted variance of assets, as a function of the number of assets in the portfolio. ${ }^{4}$

The Diversification Ratio is fairly intuitive. As the number of assets becomes large, the measure equals the average correlation coefficient between assets. If this correlation is zero, then virtually all risk is diversifiable by holding a portfolio of a large number of assets. However, when the average correlation is high, even a large number of assets cannot increase the diversification of the portfolio.

Both the Portfolio Diversification Index and Diversification Ratio are measures of diversification that relate to other measures that have been put forward in this area of literature; see Meucci (2009) for a more detailed review of diversification measures. The "differential diversification index" described by Meucci (2009) is closely related to the Diversification Ratio that we described above in Equation (2). Meucci (2009) further states that the "idiosyncratic diversification index" may be used when markets can be described by a factor model. In such case, the relative contribution of idiosyncratic risk should be low for a portfolio to be well-diversified. Bouchaud, Potters, and Aguilar (1997) and Bouchaud and Potters (2000, Chapter 3) develop the idea of an "effective asset number", a similar idea to the PDI introduced by Rudin and Morgan (2006). The effective asset number is based on the notion that portfolio optimization under incomplete information should be performed with constraints on diversification indicators. The method of Bouchaud et al. (1997) prevents the concentration of optimal portfolios, i.e. portfolios consisting of only a few stocks each with a high portfolio weight. This

\footnotetext{
${ }^{4}$ We rely here on time-series information to measure correlation. For a cross-sectional measure of correlation, see Solnik and Roulet (2000). Statman and Scheid (2008) use the return gap as a measure of diversification. The diversification ratio mentioned in Choueifaty and Coignard (2008) is different from ours, as they use the weighted average of volatilities divided by the portfolio volatility as a measure of diversification. In essence, this captures the same idea; with perfect correlation the ratio is one and with low average correlation the ratio increases. We disregard an additional dimension of diversification, time diversification, as described in Milevsky (2003).
} 
approach differs from ours. We take the number of stocks in an equally-weighted portfolio as a given, but determine which stocks to select. Fernholz and Karatzas (2008) describe the concept of diversity in financial markets. They claim that diversity-weighted portfolios lead to improved portfolio statistics. Polakow and Gebbie (2008) use a statistical criterion to attain the number of significant eigenvalues of the correlation matrix that they interpret as the number of true independent assets that investors can choose from.

The goal of our research is to show empirically that investors may benefit from using the PDI in practice, and it is not a horse-race between all diversification methods described in the literature.

\section{EMPIRICAL RESULTS}

In our analysis we compare randomly formed portfolios with well-diversified portfolios based on the PDI. We choose portfolios ranging from 5 to 30 stocks, a portfolio size which corresponds with high-conviction portfolio strategies. For each comparison, the random portfolios contain the same number of stocks as the diversified portfolios. The stocks in all the portfolios, both the diversified portfolio and the random portfolios, were equally weighted.

The random portfolios are constructed by randomly simulating 1,000 different portfolios for each year. This was done to reduce sampling risk. The characteristics of these 1,000 portfolios were then compared with those of the diversified portfolio for the same year.

The diversified portfolio is formed each year by first choosing one stock from our sample of 500 stocks. In an iterative procedure we then repeatedly add one new stock, choosing to add the one that results in the highest PDI value for the two-stock portfolio. In other words, from the remaining 499 stocks, we add the stock with the highest marginal PDI value. We keep adding the most diversifying stock to the portfolio until we reach the desired portfolio size. This procedure could be sensitive to the stock we use to start the 
iterative procedure. Therefore, each of the 500 stocks are individually used as the starting stock. From these 500 PDI portfolios, the portfolio with the highest PDI value is labelled the "diversified portfolio". We believe this procedure results in a well-diversified portfolio, but we cannot claim that it is the "optimal" diversified portfolio in the sense that it has the highest PDI value that can possibly be attained. To be certain that we have found a global optimum, we would have to calculate the PDI value for all possible combinations of portfolios of 10,20 , and 30 stocks out of 500 stocks, which is computationally infeasible.

We compare the out-of-sample diversification properties of the diversified portfolio with those of the random portfolios based on the PDI value and the Diversification Ratio. The underlying idea is that the in-sample diversified portfolio of year $t-1$ continues to be better diversified than the random portfolio in year $t$. Only if we find that using the PDI leads to better out-of-sample diversified portfolios, can it be used for practical portfolio construction by high-conviction investors.

Table 1 contains the average PDI value for each of the 1,000 simulations for portfolios ranging in size from 5 to 30 stocks.

\section{$<$ INSERT TABLE 1 ABOUT HERE >}

We observe that from 2001 to 2005 there is an increase in the PDI value of the random portfolio, followed by a slight downward trend after 2006, with the 2008 portfolio being the least diversified. This indicates that diversification benefits are smallest in crisis periods such as 2008 , which is exactly when these benefits are most wanted. This is in line with Campbell, Koedijk, and Kofman (2002), who indicate that correlations tend to increase in bear markets. This may require investors to increase the number of stocks in their portfolios in crisis times if they are to maintain diversification levels. We take the number of stocks as a given in our analyses, and leave the dynamic selection of the

\footnotetext{
${ }^{5}$ In the Appendix we show the composition of the diversified portfolios that are selected each year by means of their ticker symbols. These results indicate that the optimally diversified portfolios are not continuously loading on one particular stock.
} 
number of stocks in the portfolio for future research. We see that the pattern of PDI values is the same for each of the portfolio sizes. On average, a portfolio of 20 stocks behaves as if there are 7.4 independent stocks.

Table 2 shows the risk properties of the random portfolios when applying the market model with the equally-weighted S\&P 500 Index as a proxy for the market. We observe that the market model describes these random portfolios rather well, with R-squares of 0.785 for portfolios of 10 stocks and 0.913 for portfolios with 30 stocks. Market betas are close to unity for each of the portfolios. For a portfolio of 20 stocks, the total daily stock return volatility varies from a low of $0.79 \%$ in 2006, to a high of $3.09 \%$ in 2008 . Idiosyncratic volatility follows a similar but lower pattern, with an average of about $0.49 \%$ for 20 -stock portfolios.

\section{$<$ INSERT TABLE 2 ABOUT HERE >}

Figure 1 shows the PDI values of the diversified portfolios of 20 stocks for each year in the sample from 2001 to 2009 with green marks. The average PDI values of the 1,000 random portfolios are also displayed in blue with the red $95 \%$ confidence intervals. These confidence intervals are the empirical percentiles of the distribution of the PDIs of the randomly formed portfolios.

Even when selecting stocks on the basis of the PDI methodology, there is less diversification possible in 2008 than in each of the other years of our sample. This, again, has to do with the higher correlations between stock returns during bear markets, which makes diversification much more difficult in these periods. Unfortunately, this is exactly when diversification is most wanted. Investors may therefore want to increase the number of stocks in their portfolio during crisis periods.

For each year in the sample, except 2006, the PDI values of the diversified portfolio are statistically significantly higher than those of the random portfolio. This is striking evidence that constructing a portfolio according to the PDI does lead to better diversified 
portfolios out-of-sample. These results are independent of the financial business cycle. While diversification is more difficult in a downward trending market than in a bull market, picking stocks according to the methodology of the PDI still appears to be superior, producing a much better diversified portfolio, compared with selecting stocks randomly, .

\section{< INSERT FIGURE 1 ABOUT HERE >}

For comparison, we also display the in-sample optimal PDI values for each year in the sample. Of course, we expect that the in-sample values are higher than the out-of-sample PDI values of the diversified portfolio. This is simply because the covariance matrix structure of the daily stock returns used in the principal component analysis is not constant over time. Therefore, the construction of a portfolio in 2003 with the optimal stocks of 2002, creates a less than optimally diversified portfolio in 2003 unless our PDI algorithm finds the exact same portfolio of stocks in 2003 as in 2002, which is an unlikely outcome given the time-varying correlations and estimation errors. Our results imply that it is better, in terms of more favourable diversification properties, to use the PDI method, that is, selecting stocks now and holding them the following year in equallyweighted proportions rather than applying a naive diversification strategy in which stocks are picked in a random fashion, which is the method suggested by De Wit (1998) and DeMiguel et al (2009).

We check for robustness with respect to the number of stocks in the portfolio in Table 3. The middle part of Table 3 contains the data that are graphically displayed in Figure 1 for portfolios consisting of 20 stocks. In addition, Table 3 shows the PDI for the portfolios consisting of 10 and 30 stocks as well. We see that our results are robust with respect to the size of the portfolio. We also see, however, that the relative improvement of the PDI is somewhat larger for larger size portfolios. This is likely due to the reduction in the insample estimation risk, as estimation errors could be averaged out in larger portfolios.

$<$ INSERT TABLE 3 ABOUT HERE > 
In the previous analyses, we sorted on the PDI measure of diversification and showed that based on this technique, out-of-sample portfolios are well-diversified. As a robustness check, we also calculated whether these portfolios are well diversified under another measure of diversification. Using the Diversification Ratio that was introduced in Section 2, we show in Table 4 the out-of-sample Diversification Ratios for the portfolios formed based on the PDI. It points to the same conclusion as the results from the PDI analysis in Table 3. Overall, the Diversification Ratio of the out-of-sample portfolio, which is 0.23 on average for a portfolio of 20 stocks, is substantially lower than that of the random portfolio, which is 0.30 on average. We calculate the diversification gain as the percentage decrease in the Diversification Ratio. The diversification gain is positive in each year except 2008. For the entire period, it varies from $46 \%$ (2009) to $-13 \%$ (2008). On average, a diversification gain of about $22 \%$ can be achieved using our proposed PDI algorithm for forming better diversified portfolios. These results are robust with respect to the number of stocks in the portfolio. As indicated in Table 4, the average diversification gain is $24 \%$ for a portfolio of 10 stocks and $18 \%$ for a portfolio of 30 stocks.

\section{< INSERT TABLE 4 ABOUT HERE >}

In order to investigate the robustness of our results with respect to the investment horizon, we repeat the analysis above with a look-back and holding period of one quarter instead of one year. A quarterly holding period might be more realistic for some investors, and a shorter look-back period might better capture time-varying correlations between stock returns.

We display the results of the quarterly analysis in Figure 2. Similar to the results shown in Figure 1, we see that for most periods, the out-of-sample PDIs are larger than the 95\% percentile of the randomly formed portfolios of 20 stocks. An exception is the fourth quarter of 2005. This means that investors with quarterly holding periods may also 
benefit from using the PDI as a measure of diversification for their high-conviction investment portfolios.

\section{$<$ INSERT FIGURE 2 ABOUT HERE >}

Although we saw in Figure 1 that in the crisis year of 2008 the PDI portfolio did not diversify as expected, this problem seems to be less present in the analysis with a quarterly-based horizon. This methodology appears to be better suited to deal with timevarying correlation structures than the annually rebalanced portfolios. Thus, in the wake of a crisis scenario, with potentially fast moving interdependencies between stocks, faster rebalancing using the PDI is required to stay well-diversified.

\section{CONCLUSION}

We show that the use of a novel portfolio construction algorithm using the PDI results in well-diversified high-conviction equity portfolios, which means that fewer stocks are required to reach the same level of diversification in comparison with a portfolio of the same size with randomly selected stocks. Moreover, we investigate the out-of-sample properties of the PDI, which was proposed by Rudin and Morgan (2006), as a measure of diversification. We find that portfolios based on the PDI methodology in one year (quarter) show better diversification than portfolios of randomly chosen stocks over the next year (quarter). This is true for both out-of-sample PDI values and Diversification Ratios. Our results are robust with respect to the number of stocks in the investment portfolio or the time period under consideration. This evidence was thus far lacking in this line of literature and is of key importance for high-conviction investors who wish to make use of this measure when constructing real-life portfolios. 


\section{REFERENCES}

Agapova, A., 2009, 'Conventional Mutual Funds versus Exchange Traded Funds', Journal of Financial Markets, forthcoming

Bouchaud, J-P., and Potters, M., 2000, Theory of Financial Risk: from statisical physics to risk management, Cambridge.

Bouchaud, J-P., Potters, M., Aguilar, J-P., 1997 'Missing Information and Asset Allocation', arxiv:cond-mat/9797042

Campbell, R., Koedijk, K. and Kofman, P., 2002, 'Increased Correlation in Bear Markets', Financial Analysts Journal, Vol. 58, No. 1, pp 87-94

Choueifaty, Y., and Coignard, Y., 2008, 'Toward Maximum Diversification”, Journal of Portfolio Management, Vol 34, No. 4, pp. 40-51.

Cremers, M., and Petajisto, A., 2009, 'How Active is Your Fund Manager? A New Measure That Predicts Performance', Review of Financial Studies 22(9), pp. 3329-3365.

DeMiguel, V., Garlappi, L., and Uppal, R., 2009, 'Optimal versus Naive Diversification: How Inefficient is the 1/N Portfolio Strategy?', Review of Financial Studies, Vol 22, No. 5, pp. 1915-1953.

De Wit, D.P.M., 1998, 'Naive Diversification', Financial Analysts Journal, Vol. 54, No. 4, pp. 95-100.

Dimson, E., 1979, "Risk measurement when shares are subject to infrequent trading", Journal of Financial Economics 7, pp. 197-226.

Epps, T.W., 1979, "Co-movements in Stock Prices in the Very Short Run”, Journal of the American Statistical Association, 74, pp. 291-298

Fernholz, R., and Karatzas, I., 2008, "Stochastic Portfolio Theory: An Overview", Handbook of Numerical Analysis, forthcoming.

Malkiel, B.G., 1990, A Random Walk Down Wall Street, W.W. Norton \& Company.

Markowitz, H.M., 1976, "Markowitz Revisited", Financial Analysts Journal, vol. 32, no. 5, pp. 47-52.

Meucci, A., (2009) Managing diversication, Risk, May 2009, 74-79 (See Appendix A.1 in SSRN:http://ssrn.com/abstract=1358533)

Milevsky, M.A., 2003, 'Space-time diversification: Which dimension is better?', Journal of Risk 5(2), pp. 45-76. 
Polakow, D., Gebbie., T., 2008, 'How many independent bets are there?', Journal of Asset Management, 278-288

Rudin, A.M. \& Morgan, J.S., 2006, 'A Portfolio Diversification Index', Journal of Portfolio Management, vol. 32, no. 2, pp. 81-89.

Solnik, B. \& Roulet J., 2000, 'Dispersion as Cross-Sectional Correlation', Financial Analysts Journal, vol. 56, no. 1, pp. 54-61.

Statman, M., and Scheid, J., 2008, 'Correlation, Return Gaps, and the Benefits of Diversification’, Journal of Portfolio Management, vol. 34, no. 3, pp. 132-139. 


\section{TABLE 1:}

\section{DIVERSIFICATION CHARACTERISTICS OF RANDOMLY FORMED PORTFOLIOS}

THIS TABLE SHOWS THE AVERAGE PDI-VALUES PER YEAR OF THE 1,000 PORTFOLIOS OF RANDOMLY SELECTED STOCKS. THE PORTFOLIOS CONTAIN 5 TO 30 STOCKS. IN THE LAST ROW THE AVERAGE PDI VALUES OF THE 1,000 RANDOM PORTFOLIOS FOR EACH PORTFOLIO SIZE ARE SHOWN.

\begin{tabular}{ccccccc} 
& \multicolumn{7}{c}{ Portfolio size (\# stocks) } \\
Year & 5 & 10 & 15 & 20 & 25 & 30 \\
\hline 2001 & 2.70 & 4.37 & 5.81 & 7.16 & 8.50 & 9.78 \\
2002 & 2.51 & 3.99 & 5.34 & 6.52 & 7.54 & 8.64 \\
2003 & 2.70 & 4.45 & 6.07 & 7.57 & 8.94 & 10.31 \\
2004 & 2.94 & 5.00 & 6.86 & 8.69 & 10.36 & 11.96 \\
2005 & 3.09 & 5.31 & 7.34 & 9.08 & 10.83 & 12.65 \\
2006 & 3.02 & 5.20 & 7.16 & 9.09 & 10.94 & 12.52 \\
2007 & 2.84 & 4.72 & 6.42 & 8.05 & 9.57 & 10.95 \\
2008 & 2.21 & 3.42 & 4.43 & 5.32 & 6.22 & 7.01 \\
2009 & 2.28 & 3.51 & 4.65 & 5.69 & 6.62 & 7.60 \\
\hline average & 2.70 & 4.44 & 6.01 & 7.46 & 8.83 & 10.16
\end{tabular}




\section{TABLE 2:}

\section{RISK CHARACTERISTICS OF THE RANDOMLY FORMED PORTFOLIOS}

THE FIRST COLUMN CONTAINS THE AVERAGE BETA ESTIMATED USING THE REGRESSION $r_{p, t}^{e}=\alpha+\beta \cdot r_{m, t}^{e}+\varepsilon_{p, t}$ IN WHICH THE EXCESS PORTFOLIO RETURN OVER PERIOD T ( $r_{p, t}^{e}$ ) IS EXPLAINED BY A CONSTANT $(\alpha)$, THE MARKET RISK EXPOSURE $(\boldsymbol{\beta})$ TIMES THE EXCESS MARKET RETURN IN PERIOD T $\left(r_{m, t}^{e}\right)$, AND A RESIDUAL TERM $\left(\varepsilon_{p, t}\right)$. THE AVERAGE TOTAL DAILY VOLATILITY OF THE PORTFOLIO RETURN IS DISPLAYED IN THE NEXT COLUMN $\left(\sigma_{r}\right)$, FOLLOWED BY THE AVERAGE IDIOSYNCRATIC RETURN VOLATILITY $\left(\sigma_{\varepsilon}\right)$. THE LAST COLUMN CONTAINS THE AVERAGE R-SQUARED OF THE REGRESSIONS. WE DISPLAY THE RESULTS FOR RANDOM PORTFOLIOS OF SIZES 10, 20, AND 30 RESPECTIVELY.

Portfolio size: 10 Year Beta Total Risk Idios. risk R-sq

\begin{tabular}{rrrrr}
\hline 2001 & 1.005 & $1.76 \%$ & $0.88 \%$ & 0.743 \\
2002 & 0.997 & $2.01 \%$ & $0.94 \%$ & 0.779 \\
2003 & 1.008 & $1.30 \%$ & $0.59 \%$ & 0.796 \\
2004 & 1.008 & $0.94 \%$ & $0.48 \%$ & 0.737 \\
2005 & 0.996 & $0.88 \%$ & $0.47 \%$ & 0.717 \\
2006 & 1.009 & $0.86 \%$ & $0.46 \%$ & 0.712 \\
2007 & 0.995 & $1.16 \%$ & $0.48 \%$ & 0.825 \\
2008 & 1.003 & $3.20 \%$ & $1.08 \%$ & 0.885 \\
2009 & 1.000 & $2.33 \%$ & $0.81 \%$ & 0.874 \\
\hline average & 1.002 & $1.60 \%$ & $0.69 \%$ & 0.785
\end{tabular}

Portfolio size: 20 Beta Total Risk Idios. risk R-sq \begin{tabular}{llll}
\hline 0.995 & $1.63 \%$ & $0.62 \%$ & 0.850
\end{tabular} 0.996 1.003 0.999 1.002 1.001 1.003 $1.12 \%$ $1.000 \quad 3.09 \%$ $0.999 \quad 2.26 \%$ \begin{tabular}{ll}
0.999 & $2.26 \%$ \\
\hline 1.000 & $1.52 \%$
\end{tabular}

$\begin{array}{llll}1.003 & 1.60 \% & 0.51 \% & 0.893\end{array}$
$\begin{array}{llllll}0.67 \% & 0.871 & 1.006 & 1.87 \% & 0.56 \% & 0.908\end{array}$ $\begin{array}{llllll}0.41 \% & 0.885 & 1.003 & 1.21 \% & 0.34 \% & 0.920\end{array}$ $\begin{array}{llllll}0.34 \% & 0.847 & 0.993 & 0.84 \% & 0.27 \% & 0.892\end{array}$ $\begin{array}{llllll}0.34 \% & 0.828 & 1.000 & 0.79 \% & 0.27 \% & 0.880\end{array}$ $\begin{array}{llllll}0.33 \% & 0.827 & 1.000 & 0.77 \% & 0.27 \% & 0.879\end{array}$ $\begin{array}{llllll}0.34 \% & 0.904 & 0.999 & 1.09 \% & 0.28 \% & 0.933\end{array}$ $\begin{array}{llllll}0.78 \% & 0.936 & 1.000 & 3.06 \% & 0.63 \% & 0.956\end{array}$ \begin{tabular}{lllllll}
$0.58 \%$ & 0.932 & 0.998 & $2.23 \%$ & $0.47 \%$ & 0.954 \\
\cline { 2 - 6 } & $0.49 \%$ & 0.876 & & $1.50 \%$ & $0.40 \%$ & 0.913
\end{tabular} 


\section{FigURE 1:}

\section{DIVERSIFICATION PROPERTIES OF RANDOMLY FORMED AND DIVERSIFIED PORTFOLIOS}

THE PDI-VALUES FOR EACH YEAR ARE SHOWN FROM 2001 TO 2009. THE TRIANGLES CONNECTED BY THE GREY LINE ARE THE IN-SAMPLE PDI-VALUES FROM THE PDI PORTFOLIOS. THE CIRCLES CONNECTED BY THE GREEN LINE ARE THE OUT-OF-SAMPLE PDI-VALUES FROM THE PDI PORTFOLIOS FORMED AT THE END OF THE PREVIOUS YEAR. THE DIAMONDS CONNECTED BY THE BLUE LINE ARE THE AVERAGE PDI-VALUES FROM THE RANDOMLY FORMED PORTFOLIOS, WITH THE RED DASHED LINES INDICATING THE 95 PERCENT CONFIDENCE BOUNDS.

Out-of-sample performance of PDI for a portfolio of 20 stocks, annually rebalanced

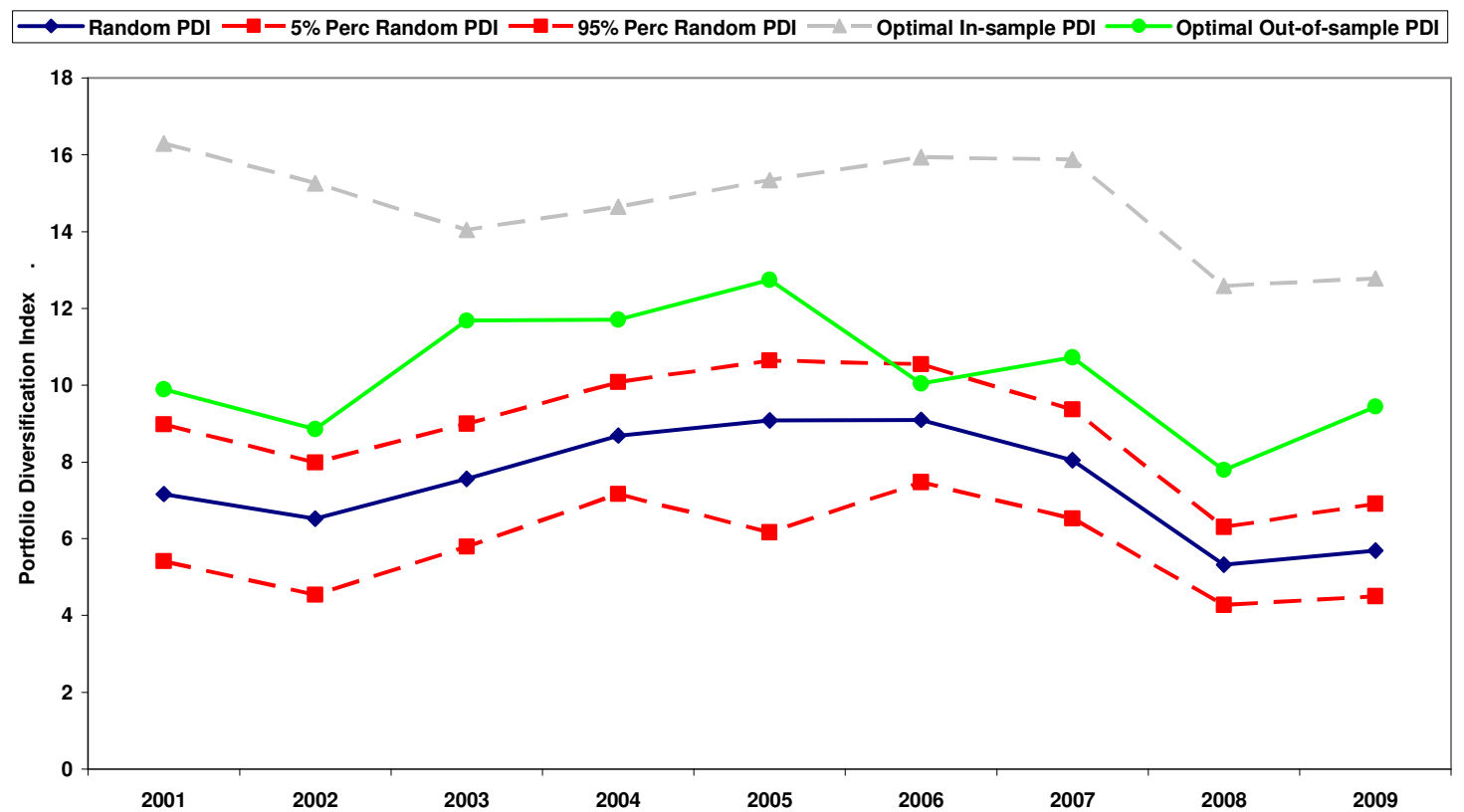




\section{TABLE 3:}

\section{PDIS OF RANDOMLY FORMED AND PDI PORTFOLIOS}

THE FIRST COLUMN CONTAINS THE AVERAGE PDI PER YEAR OF THE 1,000 RANDOMLY FORMED PORTFOLIOS. THE NEXT COLUMN SHOWS THE PDI IN THE OUT-OF-SAMPLE PERIOD OF THE DIVERSIFIED PORTFOLIO FORMED AT THE END OF THE PREVIOUS YEAR. THE LAST COLUMN INDICATES THE DIVERSIFICATION GAIN BY COMPARING THE OUT-OF-SAMPLE PDI WITH THE RANDOM PORTFOLIO'S PDI. WE DISPLAY THE RESULTS FOR RANDOM PORTFOLIOS OF SIZES 10, 20, AND 30 RESPECTIVELY.

\begin{tabular}{|c|c|c|c|c|c|c|c|c|c|}
\hline \multirow[b]{2}{*}{ Year } & \multicolumn{3}{|c|}{ Portfolio size: 10} & \multicolumn{3}{|c|}{ Portfolio size: 20} & \multicolumn{3}{|c|}{ Portfolio size: 30} \\
\hline & Random & PDI portf & Gain & Random & PDI portf & Gain & Random & PDI portf & Gain \\
\hline 2001 & 4.37 & 6.32 & $44.6 \%$ & 7.16 & 9.89 & $38.0 \%$ & 9.78 & 14.52 & $48.4 \%$ \\
\hline 2002 & 3.99 & 4.67 & $17.1 \%$ & 6.52 & 8.85 & $35.8 \%$ & 8.64 & 12.23 & $41.6 \%$ \\
\hline 2003 & 4.45 & 6.63 & $49.1 \%$ & 7.57 & 11.68 & $54.3 \%$ & 10.31 & 16.67 & $61.6 \%$ \\
\hline 2004 & 5.00 & 6.69 & $33.7 \%$ & 8.69 & 11.70 & $34.7 \%$ & 11.96 & 16.49 & $37.9 \%$ \\
\hline 2005 & 5.31 & 7.19 & $35.3 \%$ & 9.08 & 12.74 & $40.2 \%$ & 12.65 & 16.83 & $33.0 \%$ \\
\hline 2006 & 5.20 & 6.16 & $18.3 \%$ & 9.09 & 10.04 & $10.5 \%$ & 12.52 & 15.12 & $20.8 \%$ \\
\hline 2007 & 4.72 & 5.46 & $15.6 \%$ & 8.05 & 10.72 & $33.1 \%$ & 10.95 & 15.22 & $39.0 \%$ \\
\hline 2008 & 3.42 & 4.28 & $25.2 \%$ & 5.32 & 7.79 & $46.6 \%$ & 7.01 & 9.51 & $35.7 \%$ \\
\hline 2009 & 3.51 & 6.02 & $71.4 \%$ & 5.69 & 9.44 & $66.0 \%$ & 7.60 & 13.03 & $71.5 \%$ \\
\hline average & 4.44 & 5.93 & $34.5 \%$ & 7.46 & 10.32 & $39.9 \%$ & 10.16 & 14.40 & $43.3 \%$ \\
\hline
\end{tabular}




\section{TABLE 4:}

\section{DIVERSIFICATION RATIOS OF RANDOMLY FORMED AND PDI PORTFOLIOS}

THE FIRST COLUMN CONTAINS THE AVERAGE DIVERSIFICATION RATIOS PER YEAR OF THE 1,000 RANDOMLY FORMED PORTFOLIOS. THE NEXT COLUMN SHOWS THE DIVERSIFICATION RATIO IN THE OUT-OF-SAMPLE PERIOD OF THE DIVERSIFIED PORTFOLIO FORMED AT THE END OF THE PREVIOUS YEAR. THE LAST COLUMN INDICATES THE DIVERSIFICATION GAIN BY COMPARING THE OUT-OF-SAMPLE DIVERSIFICATION RATIO WITH THE RANDOM PORTFOLIO'S DIVERSIFICATION RATIO. WE DISPLAY THE RESULTS FOR RANDOM PORTFOLIOS OF SIZES 10, 20, AND 30 RESPECTIVELY.

\begin{tabular}{|c|c|c|c|c|c|c|c|c|c|}
\hline \multirow[b]{2}{*}{ Year } & \multicolumn{3}{|c|}{ Portfolio size: 10} & \multicolumn{3}{|c|}{ Portfolio size: 20} & \multicolumn{3}{|c|}{ Portfolio size: 30} \\
\hline & Random & PDI portf & Gain & Random & PDI portf & Gain & Random & PDI portf & Gain \\
\hline 2001 & 0.26 & 0.22 & $17.6 \%$ & 0.22 & 0.18 & $20.2 \%$ & 0.21 & 0.16 & $24.8 \%$ \\
\hline 2002 & 0.34 & 0.22 & $33.7 \%$ & 0.29 & 0.18 & $36.1 \%$ & 0.27 & 0.20 & $25.3 \%$ \\
\hline 2003 & 0.35 & 0.27 & $21.8 \%$ & 0.30 & 0.24 & $20.6 \%$ & 0.29 & 0.25 & $15.5 \%$ \\
\hline 2004 & 0.29 & 0.21 & $27.4 \%$ & 0.25 & 0.19 & $22.3 \%$ & 0.23 & 0.20 & $16.3 \%$ \\
\hline 2005 & 0.28 & 0.19 & $29.6 \%$ & 0.23 & 0.16 & $28.0 \%$ & 0.21 & 0.15 & $31.5 \%$ \\
\hline 2006 & 0.26 & 0.18 & $30.3 \%$ & 0.22 & 0.17 & $22.1 \%$ & 0.21 & 0.18 & $14.8 \%$ \\
\hline 2007 & 0.38 & 0.36 & $4.1 \%$ & 0.34 & 0.28 & $17.9 \%$ & 0.33 & 0.26 & $20.3 \%$ \\
\hline 2008 & 0.47 & 0.50 & $-7.1 \%$ & 0.43 & 0.48 & $-13.0 \%$ & 0.42 & 0.47 & $-13.8 \%$ \\
\hline 2009 & 0.43 & 0.19 & $55.9 \%$ & 0.40 & 0.21 & $46.2 \%$ & 0.38 & 0.26 & $31.4 \%$ \\
\hline average & 0.34 & 0.26 & $23.7 \%$ & 0.30 & 0.23 & $22.3 \%$ & 0.28 & 0.24 & $18.4 \%$ \\
\hline
\end{tabular}




\section{FigURE 3:}

\section{DIVERSIFICATION PROPERTIES OF RANDOMLY FORMED AND DIVERSIFIED PORTFOLIOS}

THE PDI-VALUES FOR EACH QUARTER ARE SHOWN FROM 2001 TO 2009. THE GREY LINE CONNECTS THE IN-SAMPLE PDI-VALUES FROM THE PDI PORTFOLIOS. THE GREEN LINE CONNECTS THE OUT-OF-SAMPLE PDIVALUES FROM THE PDI PORTFOLIOS FORMED AT THE END OF THE PREVIOUS QUARTER. THE BLUE LINE CONNECTS THE AVERAGE PDI-VALUES FROM THE RANDOMLY FORMED PORTFOLIOS, WITH THE RED DASHED LINES INDICATING THE 95 PERCENT CONFIDENCE BOUNDS.

Out-of-sample performance of PDI for a portfolio of 20 stocks, quarterly rebalanced

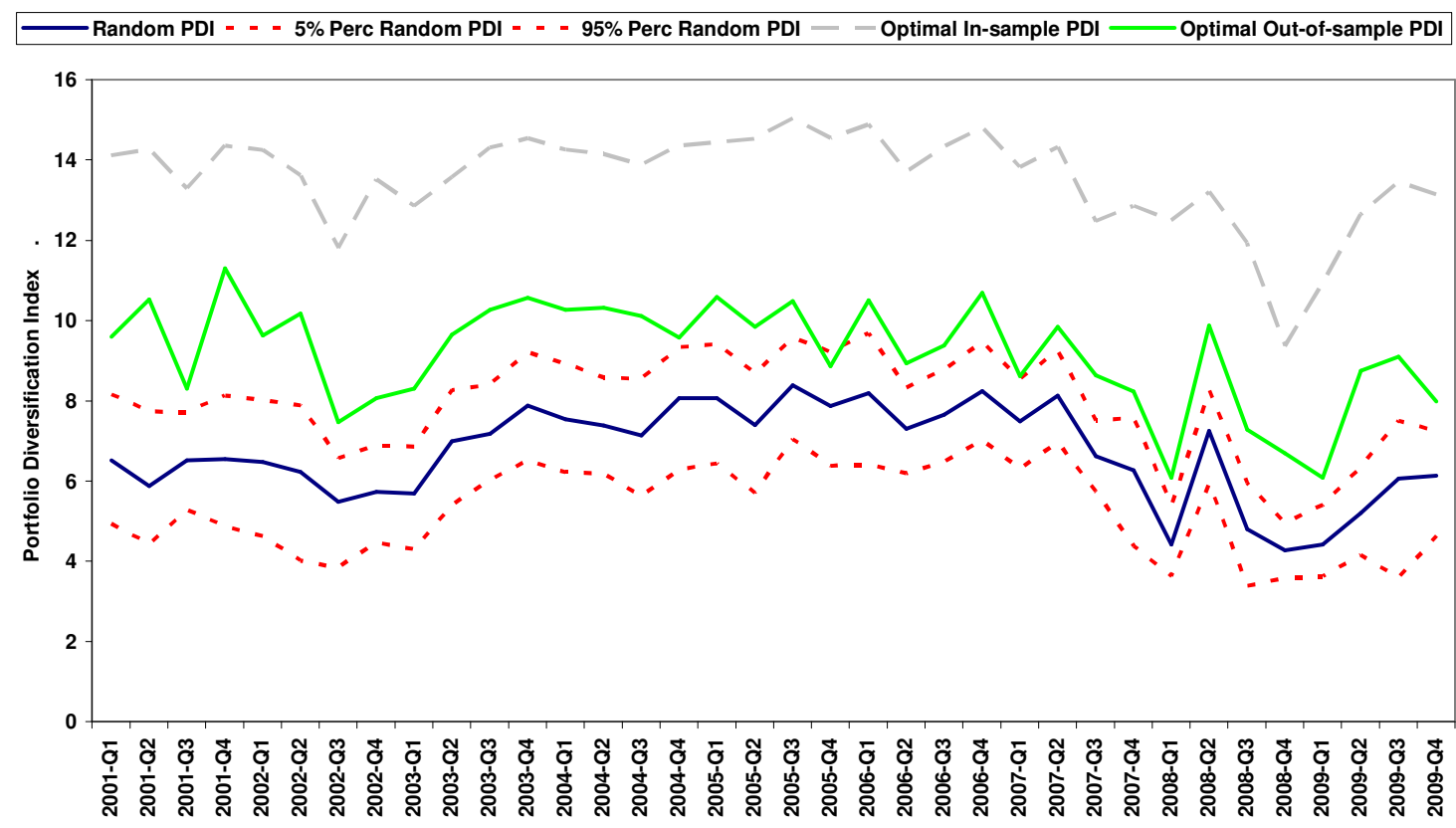




\section{Appendix}

Table A1: Tickers of the annually rebalanced 20-stock portfolio.

Tickers in bold appear twice, in consecutive years, in the diversified portfolio. Tickers underlined are at least four times in the well-diversified portfolios.

\begin{tabular}{ccccccccc}
2001 & 2002 & 2003 & 2004 & 2005 & 2006 & 2007 & 2008 & 2009 \\
\hline ABC & AAPL & ADSK & AW & ABS & AES & ACS & APOL & ADM \\
ABX & AM & BJS & CCE & ADM & AVP & AMGN & BIG & APOL \\
AET & AOC & CAH & CFC & AVP & BLL & BHI & CEG & CVS \\
BOL & BAX & Cl & EDS & CHIR & CMX & BSX & CMT & FDO \\
BSX & BMY & CSC & FRX & CSC & CPWR & DF & CVG & GENZ \\
CCE & BSX & FRX & GDT & ESRX & CSC & DRI & DFS & HRB \\
CNP & Cl & FTR & GPS & GDT & DG & EL & HUM & HRS \\
DRI & COL & GDT & HUM & KG & DGX & EXPE & JAVA & KG \\
EDS & DG & GPS & IGT & MRK & FRX & FRX & KG & LMT \\
FTR & GAS & HCA & LEG & MYL & HET & LUV & MTB & MON \\
MAT & HRB & MCD & MEDI & NCR & JNY & LXK & MXM & MYL \\
NKE & HUM & MEDI & MKC & NE & KG & MCHP & NEM & NEM \\
RX & MO & MO & MMC & NOVL & LXK & MHS & NYT & NOVL \\
SEE & MON & MON & MRK & PDCO & MAT & MYL & RLH & PBG \\
SGP & NEM & NEM & MXIM & PTV & QLGC & NYT & ROH & QLGC \\
SVU & PBG & PBG & MYL & RBK & S & Q & RSH & ROH \\
T & QTRN & SWY & TXU & THC & SWY & RX & SGP & STJ \\
TAP & TOY & TE & UIS & TLAB & SYMC & SVU & SNS & STZ \\
WM & WINN & TUP & UVN & WAT & TRB & VAR & THC & WAT \\
XL & YUM & VC & XTO & WEN & UNM & VRSN & YHOO & YHOO
\end{tabular}

